\title{
Bioethics, Law, and the Opioid Crisis: Revisiting the Concept of Incarceration versus Rehabilitation
}

Zachary J. Krauss

Cedarville University

Follow this and additional works at: https://digitalcommons.cedarville.edu/ bioethics_in_faith_and_practice

Part of the Bioethics and Medical Ethics Commons, Criminal Law Commons, Criminal Procedure Commons, Law and Economics Commons, Law and Politics Commons, Legal Ethics and Professional Responsibility Commons, and the Medical Jurisprudence Commons

DigitalCommons@Cedarville provides a publication platform for fully open access journals, which means that all articles are available on the Internet to all users immediately upon publication. However, the opinions and sentiments expressed by the authors of articles published in our journals do not necessarily indicate the endorsement or reflect the views of DigitalCommons@Cedarville, the Centennial Library, or Cedarville University and its employees. The authors are solely responsible for the content of their work. Please address questions to dc@cedarville.edu.

\section{Recommended Citation}

Krauss, Zachary J. (2019) "Bioethics, Law, and the Opioid Crisis: Revisiting the Concept of Incarceration versus Rehabilitation," Bioethics in Faith and Practice: Vol. 4 : No. 1 , Article 4.

DOI: 10.15385/jbfp.2019.4.1.4

Available at: https://digitalcommons.cedarville.edu/bioethics_in_faith_and_practice/vol4/iss1/4 


\title{
Bioethics, Law, and the Opioid Crisis: Revisiting the Concept of Incarceration versus Rehabilitation
}

\begin{abstract}
The opioid crisis has taken America by storm and is causing more deaths each year than ever originally anticipated. Our current approach to addressing the opioid crisis involves two separate approaches, one from the medical/rehabilitation side of the problem, and one from the criminal justice side. This article serves as a revisiting of the discussion of the intricate balance that must be reached between rehabilitation and incarceration in order to adequately address the problem.
\end{abstract}

\section{Keywords}

Opioid Crisis, Bioethics, Law, Opioid, Incarceration

\section{Creative Commons License}

(c) (i) $\Theta \Theta$

This work is licensed under a Creative Commons Attribution-Noncommercial-No Derivative Works 4.0 License. 


\title{
Bioethics, Law, and the Opioid Crisis:
}

\section{Revisiting the Concept of Incarceration versus Rehabilitation}

\author{
Zach Krauss
}

Cedarville University

\section{Introduction}

The opioid crisis has taken the country by surprise over the past decade or so. Since the issue has become relevant because of its danger to the public, more and more information has become available about not only the dangers for addicts, but also for affected families and friends. The opioid crisis has caused at least 600,000 deaths to date, and is expected to increase to almost 800,000 by $2020 .{ }^{1}$ Opioid addiction afflicts about 10 percent of the approximately 20 million United States residents who struggle with substance abuse disorders. ${ }^{2}$ The 2017 UN report on narcotic use shows that the United States is a significant outlier compared to other countries. The US leads the world in narcotic use by $50 \%$ over the second place country, Germany. ${ }^{3}$ The Organisation for Economic Cooperation and Development (OECD) reports that the availability of opioid medications in the US is much higher than in other countries. The US is ahead of Germany by over 20,000 defined daily doses for statistical purposes (S-DDD) per million inhabitants, almost double the roughly 23,000 S-DDD measured in Germany in $2011 .^{4}$

1 Max Blau, "Opioids could kill nearly 500,000 Americans in the next decade," https://www.statnews.com/2017/06/27/opioid-deaths-forecast/. June 27, 2017. Accessed August 16, 2017.

2 American Society of Addiction Medicine, "Opioid Addiction 2016 Facts and Figures," American Society of Addiction Medicine (2016).

3 International Narcotics Control Board, "Narcotic Drugs - Technical Report," Accessed 4/13/2019. https://www.incb.org/incb/en/narcotic-drugs/Technical_Reports/narcotic_drugs_reports.html

4 Organisation for Economic Cooperation and Development, "Opioids use," Accessed 10/10/2019. https://www.oecd-ilibrary.org/sites/652ef96a-en/index.html?itemId=/content/component/652ef96aen\&mimeType $=$ text/html

Bioethics in Faith and Practice vol. 4 no. 1, pp. 29-29. ISSN 2374-1597 (C) 2019, Heather Kuruvilla, licensed under CC BY-NC-ND (http://creativecommons.org/licenses/by-nc-nd/4.0/ ) 


\section{The Current State of Law and Practice in the US}

\section{For drug abuse in general}

There are many laws that apply to those who struggle with drug abuse and substance use disorders. Title 21 United States Code (USC) Controlled Substances Act designates that it is unlawful for any non-medical professional or dispenser to manufacture, distribute, or produce a controlled substance in any situation. The Drug Enforcement Administration (DEA) has a division known as the Office of Diversion Control which is responsible for enforcing this act. ${ }^{5}$

There has been a large increase in the number of those under some form of criminal justice supervision in the past twenty years. ${ }^{6}$ Along with this, it seems that this increase in a population of those under supervision is indicative of a larger shift toward more strict laws and penalties associated with drug-related offenses. ${ }^{7}$

\section{For overdose and opioid addiction}

In August 2017, President Trump announced that he wanted to declare a state of national emergency as a response to the impending danger of the opioid crisis. ${ }^{8}$ It is clear that opioid addiction is something that is being addressed on a national and international scale, but currently, our mainline method for addressing the opioid crisis is incarceration. Incarceration for opioid addiction is not necessarily the only option that the

\footnotetext{
${ }^{5}$ Title 21 United States Code (USC) Controlled Substances Act, Drug Enforcement Administration Diversion Control Division, Accessed 04/11/2019. https://www.deadiversion.usdoj.gov/21cfr/21usc/index.html

${ }^{6}$ Lauren Glaze, Thomas Bonczar, "Probation and Parole in the United States, 2005," Washington, DC: Office of Justice Programs, Bureau of Justice Statistics; 2006. Dept of Justice.

${ }^{7}$ Eric Jensen, Jurg Gerber, Clayton Mosher, "Social consequences of the War on Drugs: the legacy of failed policy," Criminal Justice Policy Review. 15, no. 1 (2004): 100-121.

8 Donald Trump, "President's Commission on Combating Drug Addiction and the Opioid Crisis," Interim Report. Washington, DC (2017). Accessed 04/15/2019, https://www.whitehouse.gov/ondcp/presidents-commission.
} 
Bioethics in Faith and Practice • $2019 \bullet$ Volume 4 • Number 1

United States' criminal justice system uses in order to combat the issue. Treatments such as therapeutic substitutes for incarceration, treatment with prison- and jail-based oversight, and reentry programs to help with transition from incarceration into society once again have all been utilized. ${ }^{9}$ Cognitive therapies that help with coping and decision-making skills are some of the most effective therapies available, so behavioral treatments have been utilized in the past.

The current state of the criminal justice system in regard to addicts and substance abusers does not allow much opportunity for treatment. Of state inmates, who make up the majority of incarcerated individuals, $15 \%$ of them received treatment for drug abuse, while more than $50 \%$ of them met the criteria for treatment. While many of the treatment options for addiction that can be utilized for offenders and are effective, a majority of prisons and jails do not, and many addicts continue to suffer as a result. ${ }^{10}$ While the researchers don't advocate for any strong changes in the justice system itself, they stress that unless the criminal justice system changes the way it reacts to addiction and opioid abuse, the problem will only continue to grow and incarceration rates will increase year after year. ${ }^{11}$

\section{Advocacy for Change in America Based on International Standards}

\section{How drug addiction is handled in other countries}

\footnotetext{
${ }^{9}$ Kevin Knight, David Farabee, "Treating Addicted Offenders: A Continuum of Effective Practices," Kingston, NJ: Civic Research Institute (2004)

${ }^{10}$ Redonna Chandler, Bennett Fletcher, and Nora Volkow, "Treating Drug Abuse and Addiction in the Criminal Justice System: Improving Public Health and Safety," JAMA 301, no. 2 (2009): 183-190

${ }^{11}$ Ibid.
} 
Bioethics, the Law, and the Opioid Crisis

In 2001, Portugal became the first European country to eliminate all criminal penalties for personal drug possession.. Researchers provided therapy to drug users rather than prison or jail sentences. ${ }^{12}$ Researchers found that not only had use decreased in adolescents, but HIV infections and deaths related to heroin had also decreased by almost half. The number of people who were actively seeking treatment had doubled, showing their central goals of the decriminalization had been achieved. ${ }^{13}$ These results can be attributed to Portugal's renewed focus on harm reduction strategies in addition to widespread education about opioid use and its danger.

In the late 1990s, Switzerland decided to stop trying to fight the use of drugs in their country, but rather to focus on the importance of caring for those who struggle with substance abuse. The country implemented legalized drug consumption rooms and heroin-assisted treatment facilities to attempt to make the use of drugs in the country safe. The number of opioid-related deaths in Switzerland has decreased by over 60 percent, and HIV infections also significantly dropped. ${ }^{14}$ The Swiss government has a strong focus on allowing as many people into treatment in order to reduce harm as possible.

\section{How those forms of legislation would look in America}

What would it look like to implement similar rules and legalizations in the US? It's clear that the United States is one of the worst cases of an opioid crisis in the world, and that the current methods being utilized are not functioning effectively enough to make a substantial difference. However, wouldn't completely abolishing certain punishment levels from American justice system practice solve the problem? It's true that decriminalizing illicit drugs in some European countries has helped to curb addiction and assist in

\footnotetext{
${ }^{12}$ Caitlin Hughes \& Alex Stevens, "The effects of the decriminalization of drug use in Portugal. Discussion paper." The Beckley Foundation, Oxford (2007)

${ }^{13}$ Glenn Greenwald, "Drug decriminalization in portugal: lessons for creating fair and successful drug policies," CATO Institute (2009).

14 Addiction | Suisse “Addiction Suisse "Facts and Figures" Accessed 04/13/2019. https://faitschiffres.addictionsuisse.ch/fr/opioides/consequences/injections-mortalite.html
} 
Bioethics in Faith and Practice • $2019 \bullet$ Volume 4 • Number 1

decreasing overdose levels, but that does not necessarily translate into our American culture the exact same way. In order to discover the efficacy of such means, etc., it would be crucial for studies to be done in small populations before widespread implementation could occur. Either way, it seems clear from the literature that decriminalization has promise in this field, as long as it is accompanied by shifts in treatment and care that allow individuals access to methods and interventions that will allow them to recover.

Legislation similar to this kind of decriminalization has been occurring for years relating to marijuana use. The use of marijuana has become legal in many states for various uses, and the long-term effects of this legislation has yet to be researched in full. Being able to see how these changes affect the public could play a huge role in helping to decide how legislation should move forward in the world of legalization of opioid medications. Of course, marijuana and opioid use are two very separate issues, and it's impossible to compare them directly, even if decriminalization of marijuana is successful in a cost-risk scenaria. The concepts could be compared and then pros and cons from marijuanas legalization could potentially be applied to any future legislation related to opioid use.

Future research needs to be done in order to establish which forms of care and treatment are the most efficient along with research proving weather or not localized decriminalization is effective for curbing overdose and addiction cases. In addition, further research would need to be done in different geographical areas of the country in order to determine whether or not such legislation would need to be on a federal or state level. While we all share the same country, America's landscape as far as reasons for opioid abuse is different in each state and even in each region, so those considerations need to be made.

\section{Bioethical Discussion and Future Research on Treatment and Care}

Mental health and substance use disorder (SUD) are incredibly important aspects of any discussion related to the opioid crisis. It has been shown that mental health disorders are closely associated with problem drug 
Bioethics, the Law, and the Opioid Crisis

use in the community. ${ }^{15}$ More than half of the prescription opioids in the US are prescribed to the $16 \%$ of Americans that suffer from a mental health disorder of some kind. ${ }^{16}$ These kinds of statistics should tell us that addressing mental health in America with regard to the opioid crisis is an extremely important topic. Further, the prescribing of opioid medications in patients with mental health disorders must be addressed and quelled in order to prevent those who are already at risk of problem drug use from getting their hands on the medications they could abuse.

One issue that arises in discussions about the future of treatment and care for addicts across the nation is the use of supervised injectable opioid assisted treatment (siOAT) to aid the addict. Utilizing this kind of a program allows those struggling with substance use disorder to take their medications in a stable environment with the help of a medical professional. Literature has shown that siOAT is effective for several outcomes including "retention in treatment, reducing the use of street drugs, and reducing illegal activities." 17 This brings with it ethical questions of whether treatment programs like this are enabling the user, along with the questions about the long-term efficacy of this and other similar programs. Further research must be done in order to establish justification for siOAT.

While addressing incarceration and criminal justice programs is a great place to start when considering the opioid crisis, it is important to understand that the issue itself is complex and multi-faceted. There is not one solution that can fix the problem. The American Journal of Public Health describes the etiology of opioid addiction as addicts using opioids as "a refuge from physical and psychological trauma, concentrated disadvantage, isolation, and hopelessness." ${ }^{18}$ The article continues by saying that overreliance on opioid

\footnotetext{
${ }^{15}$ Mark Sullivan et al., "Association between mental health disorders, problem drug use, and regular prescription opioid use." Archives of Internal Medicine, 166: 2087-2093.

${ }^{16}$ Matthew Davis, Lewei Lin, Haiyin Liu, and Brian Sites, "Prescription opioid use among adults with mental health disorders in the United States." The Journal of the American Board of Family Medicine. 30, no. 4 (2017): 407-417.

${ }^{17}$ Public Health Ontario, "Effectiveness of supervised injectable opioid agonist treatment (siOAT) for opioid use disorder.

${ }^{18}$ Nabarun Dasgupta, "Opioid Crisis: No easy fix to its social and economic determinants," American Journal of Public Health, 108, no. 2 (2018): 182.
} 
Bioethics in Faith and Practice • 2019 •Volume 4 • Number 1

medications is "emblematic of a health care system that incentivizes quick, simplistic answer to complex physical and mental health needs," and that "simplistic measures to cut access to opioid offer illusory solutions to this multidimensional society

It is clear that the opioid epidemic is one that is fueled not only by improper treatment of addicts, but also by a predisposition of a large demographic of the United States to addiction as a result of things such as mass trauma, isolation, and learned helplessness. As these factors continue, no amount of criminal justice reform will cure the problem. Instead, the approach to the war on drugs needs to be one that comes from many angles and addresses many problems at once, rather than trying to use any one plan.

In an article published in the Journal of Pain Research, Schatman describes a discrepancy between opioid marketing and observed effects. One particular analgesic, OxyContin, was marketed by Purdue Pharma as having a less than $1 \%$ chance risk of addiction. While this number seems promising and would advocate for the use of OxyContin in many situations, the same study noted that in 2008 alone, the number of nonmedical users of OxyContin increased by almost half a million. This article poses that this deception in the marketing of various opioid medications could be a strong contributor to the great growth of the opioid crisis in America in recent years. ${ }^{19}$ The same article looks at the fact that while many options for curbing the opioid crisis have been introduced to the public and the medical profession in the past few years, many of them show few or no benefits for patients themselves and a lack of actual positive change in the actual statistics of the crisis.

One alternative to many of the traditional methods of curbing opioid use that the article discusses is the use of tamper-resistant/abuse-deterrent formulations (TR/ADFs) that have the potential to reduce levels of overdoses, addiction cases, and deaths. ADFs specifically were extremely effective in decreasing risk for

\footnotetext{
${ }^{19}$ Michal Schatman, "The Health Insurance Industry: Perpetuating the Opioid Crisis through Policies of Costcontainment and Profitability," Journal of Pain Research 8, (2015): 153-158.
} 
Bioethics, the Law, and the Opioid Crisis

development of abusive tendencies as well as for overdoses, yet the insurance industry has chosen not to market for these formulations at all. ${ }^{20}$ This kind of a focus points to a focus from industry toward profitability and cost-containment rather than toward true patient care and risk assessment. What's worse is that in this context, these tactics in the end did not make the insurance companies any more money than they might have made before because the overdoses and addiction cases caused by the use of "normal" formulary drugs continued to raise hospital stay costs and the costs of other interventions.

While many institutions that deal with addicts and the opioid are required to fight for patient benefit and care, it seems that in many ways other institutions only fight for themselves and completely ignore the need that is present in potential abusers lives. It has been shown that incarceration alone is not the solution for the opioid crisis. Whether utilizing incarceration with better prevention and treatment methods, or completely decriminalizing illicit substances and focusing completely on treatment, the truth is that the focus must lie solely on the individual struggling with the disease of addiction, not on their action of using. As long as that kind of a respect for an individual's needs are retained, the opioid crisis has a chance to improve.

\section{Conclusion}

The Bible is clear in many places that we are to remain sober and clear-minded in all areas of life. 1 Peter 1:13 says that we are to remain alert and fully sober, so that we can be fully focused on Christ and His return. While the Bible says that there are no temptations that will push us beyond what we can bear (1 Cor. 10:13), it's clear that we need to have a more integrated approach if we are going to fight against the opioid crisis. In this same vein, we have to find ways to address the issue before it becomes one.

\footnotetext{
${ }^{20}$ Ibid.
} 
From the literature, it is very clear that America is suffering in many ways because of the opioid epidemic. Families are being wrecked, and the jails and prisons are being overcrowded, and the nation still experiences yearly increases in the number of addicts and opioid-related overdoses. In this paper we have discussed not only some of the origins of the problem in America, but also some of the solutions posited by European countries such as Switzerland and Portugal. After examining those acts of legislation, the ramifications of implementing such legislation in America was discussed before entering into a bioethical discussion about the opioid epidemic and the place for treatment such as supervised injectable opioid assisted treatment. While there are various ways to treat or prevent opioid addiction, it is difficult to find a method that works in every area of the country for every kind of patient, so careful examination of the options and the ways in which those options can be differentiated for use all over the country is important before moving forward with any legislation. America obviously has a lot of room to grow, and there are years ahead of fighting for sobriety for the people, but the literature shows that if we focus only on incarceration and criminal justice rather than treatment of individuals, the epidemic itself will only grow. 
Bioethics, the Law, and the Opioid Crisis

\section{Reference}

Addiction | Suisse. "Addiction Suisse "Facts and Figures" Accessed 04/13/2019. https://faitschiffres.addictionsuisse.ch/fr/opioides/consequences/injections-mortalite.html

American Society of Addiction Medicine. "Opioid Addiction 2016 Facts and Figures." American Society of Addiction Medicine (2016).

Blau, Max. "Opioids could kill nearly 500,000 Americans in the next decade." https://www.statnews.com/2017/06/27/opioid-deaths-forecast/. June 27, 2017. Accessed August 16, 2017.

Chandler, Redonna. Fletcher, Bennett and Volkow, Nora. "Treating Drug Abuse and Addiction in the Criminal Justice System: Improving Public Health and Safety.” JAMA 301, no. 2 (2009): 183-190.

Dasgupta, Nabarun. "Opioid Crisis: No easy fix to its social and economic determinants." American Journal of Public Health, 108, no. 2 (2018): 182.

Davis, Matthew et al. "Prescription opioid use among adults with mental health disorders in the United States.” The Journal of the American Board of Family Medicine. 30, no. 4 (2017): 407-417.

Glaze, Lauren. Bonczar, Thomas. "Probation and Parole in the United States, 2005."

Washington, DC: Office of Justice Programs, Bureau of Justice Statistics (2006) Dept of Justice.

Greenwald, Glenn. "Drug decriminalization in portugal: lessons for creating fair and successful drug policies," CATO Institute (2009).

Hughes, Caitlin \& Stevens, Alex. "The effects of the decriminalization of drug use in Portugal. Discussion paper.” The Beckley Foundation, Oxford (2007).

International Narcotics Control Board. "Narcotic Drugs - Technical Report.” Accessed 4/13/2019. https://www.incb.org/incb/en/narcotic-drugs/Technical Reports/narcotic drugs reports.html

Jensen, Eric. Gerber, Jurg. Mosher, Clayton. "Social consequences of the War on Drugs: the legacy of failed policy." Criminal Justice Policy Review. 15, no. 1 (2004): 100-121. 
Bioethics in Faith and Practice • $2019 \bullet$ Volume 4 • Number 1

Knight, Kevin. Farabee, David. "Treating Addicted Offenders: A Continuum of Effective Practices.” Kingston, NJ: Civic Research Institute (2004).

Organisation for Economic Cooperation and Development, "Opioids use," Accessed 10/10/2019. https://www.oecd-ilibrary.org/sites/652ef96a-en/index.html?itemId=/content/component/652ef96a$\underline{\text { en\&mimeType }=\text { text/html }}$

Public Health Ontario, "Effectiveness of supervised injectable opioid agonist treatment (siOAT) for opioid use disorder.

Schatman, Michal. "The Health Insurance Industry: Perpetuating the Opioid Crisis through Policies of Cost-containment and Profitability.” Journal of Pain Research 8, (2015): 153-158.

Sullivan, Mark. "Association between mental health disorders, problem drug use, and regular prescription opioid use.” Archives of Internal Medicine, 166: 2087-2093.

Title 21 United States Code (USC) Controlled Substances Act, Drug Enforcement Administration Diversion Control Division, Accessed 04/11/2019. https://www.deadiversion.usdoj.gov/21cfr/21usc/index.html

Trump, Donald. "President's Commission on Combating Drug Addiction and the Opioid Crisis." Interim Report. Washington, DC (2017). Accessed 04/15/2019. https://www.whitehouse.gov/ondcp/presidents-commission. 